\title{
Author Correction: Ancient genomes indicate population replacement in Early Neolithic Britain
}

Selina Brace, Yoan Diekmann, Thomas J. Booth, Lucy van Dorp D, Zuzana Faltyskova, Nadin Rohland, Swapan Mallick, Iñigo Olalde, Matthew Ferry, Megan Michel, Jonas Oppenheimer, Nasreen Broomandkhoshbacht, Kristin Stewardson, Rui Martiniano (D), Susan Walsh, Manfred Kayser (iD), Sophy Charlton (D), Garrett Hellenthal, lan Armit (D), Rick Schulting, Oliver E. Craig (D), Alison Sheridan, Mike Parker Pearson, Chris Stringer (D), David Reich, Mark G. Thomas (D) and lan Barnes (iD)

Correction to: Nature Ecology \& Evolution https://doi.org/10.1038/s41559-019-0871-9, published online 15 April 2019.

In the version of this Article originally published, there were errors in the colour ordering of the legend in Fig. 5b, and in the positions of the target and surrogate populations in Fig. $5 \mathrm{c}$. This has now been corrected. The conclusions of the study are in no way affected. The errors have been corrected in the HTML and PDF versions of the article. 


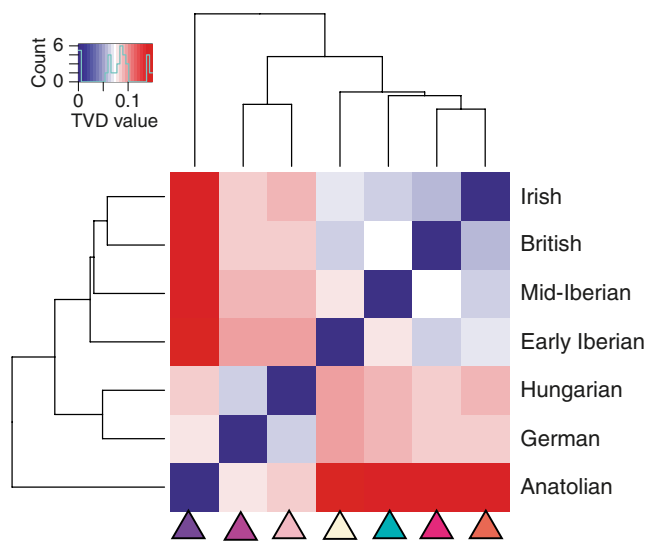

Original

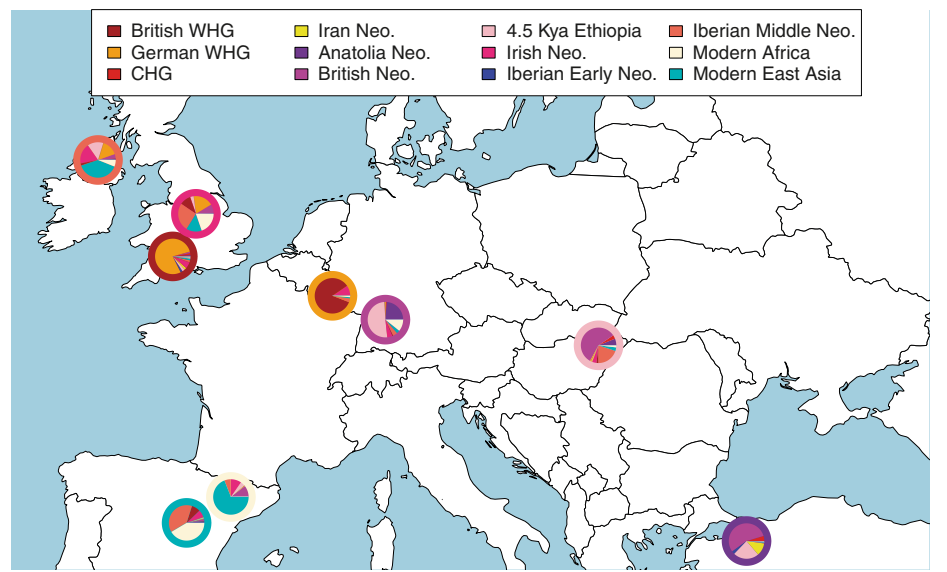

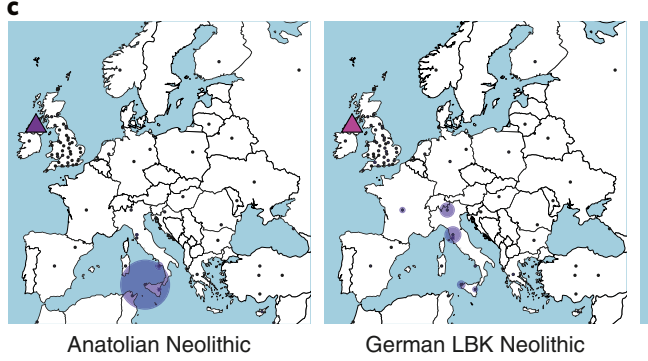
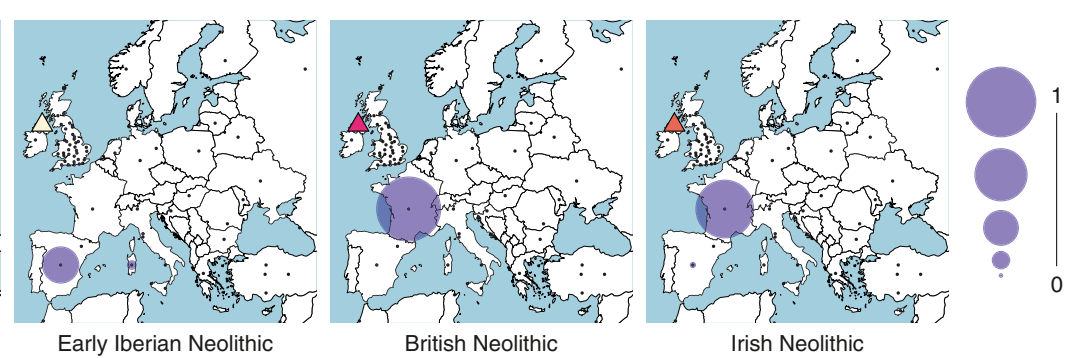

Corrected

a

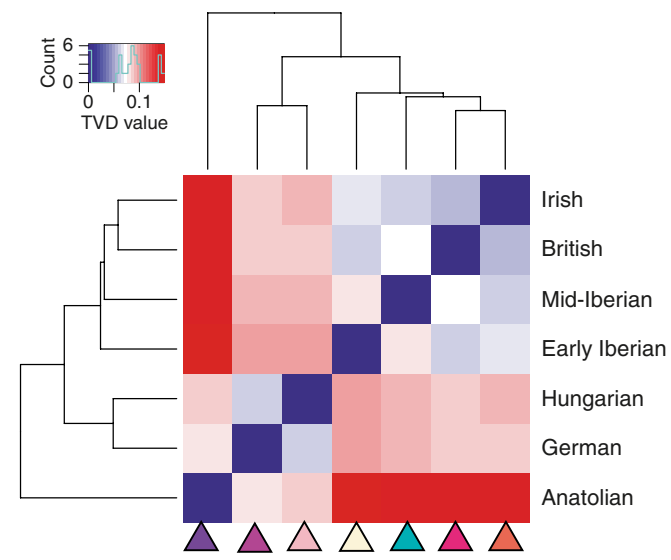

b

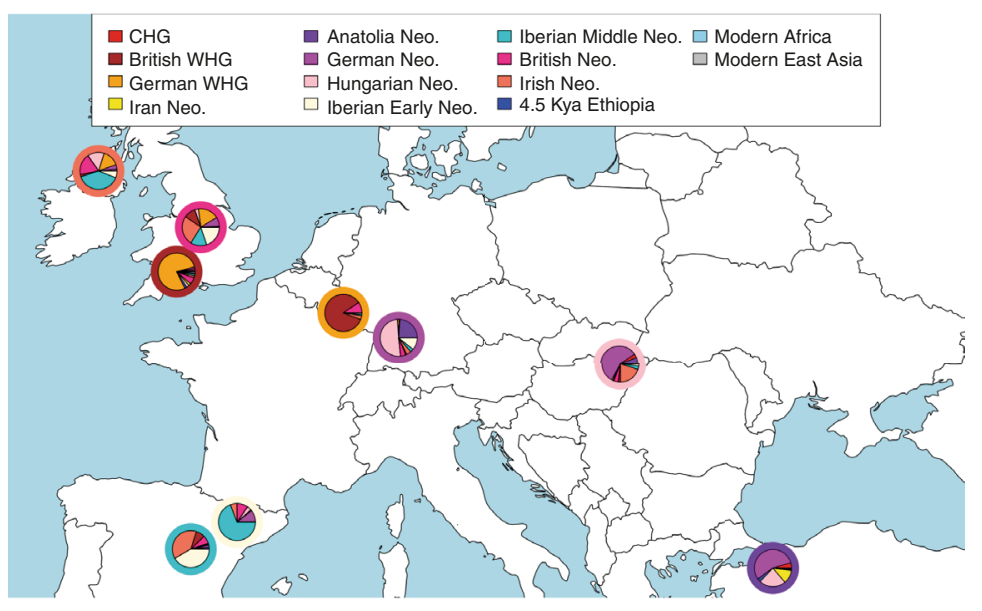

c

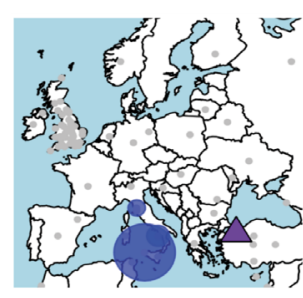

Anatolian Neolithic

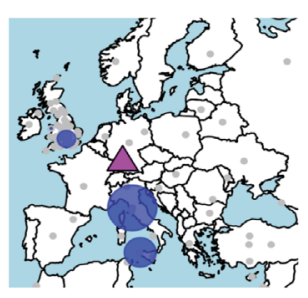

German LBK Neolithic

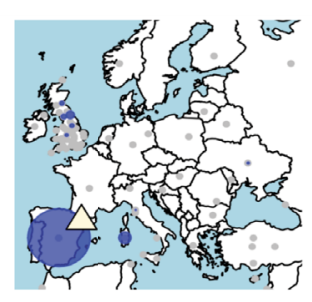

Early Iberian Neolithic

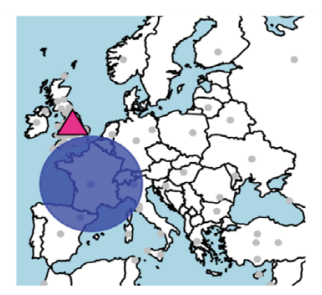

British Neolithic

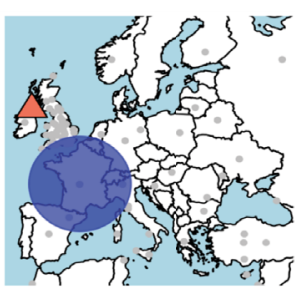

Irish Neolithic

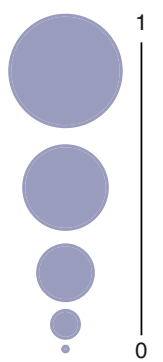

Fig. 5 | Original and Corrected.

Published online: 8 May 2019

https://doi.org/10.1038/s41559-019-0912-4 